\title{
Raising safety and productivity in underground mining via thermal imaging
}

\author{
by Sebastian Graszk, Tobias Wendel, Dr.-Ing. Ralph Baltes, Univ. Prof. Dr.-Ing. Elisabeth Clausen \\ Institute for Advanced Mining Technologies, RWTH Aachen University, Germany, 52062 Aachen, Germany, \\ sgraszk@amt.rwth-aachen.de
}

\begin{abstract}
Underground mining is essential for the supply of primary raw materials, which are essential to ensure modern prosperity and growth. Since mining operations are known to be costly and potentially hazardous, mining processes offer tremendous potential for technology driven improvements to enable increased safety of workers and operational productivity. These developments slowly announce a new era of mining technology that is reflected in the term Mining 4.0. This paper introduces different approaches for raising safety and productivity in mining via thermal imaging. The underground testing results from our demonstrator indicate that thermal imaging based systems may become a cuttingedge technology on the way to autonomous mining processes.
\end{abstract}

\section{Introduction}

When thinking of underground mining, most people imagine dusty, dirty, dark and dangerous working environments. Indeed, miners often have to handle challenging environmental conditions while dealing with huge equipment and last but not least the transport of big masses in partly unpredictable situations. To increase the safety and productivity of a mine simultaneously, the digitization and automation of specific mining processes is of fundamental importance. One emerging technology in terms of the digitalization of mining processes and the core of this paper is thermal imaging. Even though many of the following examples and statements may be applicable to both, surface and underground mining, this paper as well as the applications described focuses on underground mining. In the following chapters, first the challenges and process optimization in mining are discussed. Afterwards, the Institute for Advanced Mining Technologies (AMT) and the Sustainable Intelligent Mining Systems (SIMS) project are introduced. Subsequently, the optimization tasks, the underground geological conditions and the underground testing results generated from the SIMS project are presented. The paper ends with a conclusion of the main results and an outlook on further research opportunities.

\section{Mining's challenges}

Thermal imaging has become a widely used sensor technology for process optimization as part of non-destructive testing in e.g. quality control and several industrial applications over the past years [1]. The visualization of thermal effects but also the robustness and reliability of this technology, as well as a remarkable price drop of thermal cameras are likely reasons for thermal imaging to become a highly promising sensor technology for many industries. Nevertheless, only few applications of thermal imaging can be found in literature and industrial application that deal with process optimization in mining $[2,3]$. To understand the advantages and disadvantages of using thermal imaging in underground environments, mining processes are compared to regular factory based production processes.

Before explaining the particularities, it is to mention that there are two fundamental different ways to extract minerals within underground mining operations. On the one hand, there are continuous extraction processes, in which a part of the deposit is mined by continuous cutting it with specially designed machines. On the other hand, there are discontinuous mining processes to extract processes such as drilling and blasting operations. In drilling and blasting, the material is to loose by blasting a part of the mine face by the help of explosives which are induced into predrilled holes. Decisive factors for a mining method to be use are a combination of technical and economical aspects that strongly depend on a mineral deposits type. Mostly independent on the loosening method, the extracted material is to transport out of the mine and to process in the following before becoming a product ready for sale [4].

First, the environmental conditions such as air temperature and moisture contents and air pressure as well as the air's chemical composition are rarely constant and therefore difficult to control. Air temperatures may vary between $20^{\circ} \mathrm{C}$ and $50^{\circ} \mathrm{C}$ within a single mine for example. The necessary cooling of underground workings strongly depends on factors like the depth below surface, seasons, daytime and outside weather conditions but also the used equipment, number of workers underground and so on. The air's chemical composition may sometimes be harmful to miners in the case of high $\mathrm{NOx}$ or $\mathrm{CO}$ contents from the diesel combustions engines of the mining equipment and critical detonation gases of explosives. In some cases - e.g. in hard coal mining - the air's composition might even become explosive due to methane gas emissions caused by the coal deposit itself. Thus, fresh air needs to be ventilated into a mine from the surface. Nevertheless, it is not possible to achieve "clean" surface, ground floor and air working conditions due to uncovered surfaces of machines, equipment or even the mines face itself. Thus, the air is often loaded with dust, which means auerosoles move through a mines air with high velocities. Finally yet importantly, underground mining does not offer ambient natural sun light [4].

Second, mining processes differ in correlation with their imperfection and uncertainty of the available information about the product to be mined as well as the knowledge of to the valuable contents, spatial distribution, presence of natural 
gases and many more aspects. Mineral deposits were formed and often restructured and disturbed in geological processes that started several hundred million years ago. For that reason, each mineral deposit is unique. Consequently, mineral concentration and the thickness of geological layers vary. With this, several factors like the need of special roof and wall support but also the presence of valuable or even dangerous accompanying minerals come along. All these factors contribute to make mining processes partly unpredictable in terms of constant production quality and quantity [3].

Third, the logistics in mining differ from the logistics in other production processes in some major aspects. One of these aspects is that the extraction faces are dynamic as they follow the geology of the deposit. Therefore, factors like equipment allocation but also intense flexibility of haulage and transportation processes have to be considered. Furthermore, one has to bear in mind that a mine's output (extracted mineral) is typically many times larger as the input (machines, fuel, construction material). Thus, optimized conveying processes in underground mining are important, yet hard to control [4].

To summarize, running an underground mine is a highly complex task, influenced by an innumerable number of factors. Not only the mineral extraction but also the haulage and transportation just like several subjects of health and safety are to keep in mind. Process optimization in order to improve productivity and safety shall thus not to be seen as an isolated issue, but as embedded in the organism of a mine's overall operation. This is why all the above-mentioned characteristics of underground mining offer an enormous potential for the implementation of smart machinery and services through the intelligent use of data acquired being delivered by ruggedized sensor technologies.

The unique working and process conditions under which mining takes place necessitate particular demands on the used sensor technologies. Firstly, sensors used in mining have to stand the aforementioned harsh environmental conditions. Therefore, robust camera systems as well as specially designed housings are compulsory. To handle the challenge of geological uncertainty, passive sensor technologies that cover a large area with quick measurements are favourable. Finally yet importantly mining operations take place at numeral different positions within a mine at the same time. Thus, a cost-efficient sensor technology is to use, to cover the large number of possible implementations.

\section{Our approach}

The Institute for Advanced Mining Technologies (AMT) at RWTH Aachen University, Germany, conducts research and teaching in the field of automation and digitization of mining machinery and processes targeting at safe, efficient and responsible mining practices. AMT focuses on the advancement and industrial scale application of several sensor technologies, especially Acoustic Emission (condition monitoring as well as material characterization), UltraWideband (positioning and emergency communication) as well as thermal imaging. Thermal imaging was successfully used e.g. to navigate and control a shearer [5], to monitor, detect and correct conveyor belt positions [6], to classify material flows [7] and rock surfaces and other applications in harsh conditions of mining processes. Over the past years, AMT thus gained a deep expertise of thermal imaging in mining environments and thermal image processing under the rough conditions of mining processes. During this time, AMT developed mining approved technologies that mechanically and electrically withstand harsh mining conditions. By knowing the peculiarities of thermal imaging in an mining environment, it has become possible to solve complex optimization challenges through robust data processing $[4,5]$. To realize a safe, efficient and reliable raw material supply, AMT not only focusses on the present but also evaluates future challenges in the field of mining. Future challenges are related closely to the accessibility of the minerals underground. The fact that many ore rich mineral deposits have been depleted over the past decades leads to the current and future trend for mining in greater depths for lower ore grades in more complex orebodies.

One research project that directly addresses the aforementioned future mining challenges is the European Union Horizon 2020 funded SIMS (Sustainable and Intelligent Mining Systems) project under the grant agreement No. 730302. The projects scope is to create a long lasting impact on technologies and solutions for the mining industry. The consortium ranges from mining companies, system and equipment OEMs to leading universities such as the RWTH Aachen University. This multidisciplinary project aims to boost development and innovation to create Sustainable Intelligent Mining Systems [8].

Within the SIMS project, AMT uses thermal imaging based on long-wavelength infrared (LWIR) cameras for mass flow characterisation, crack detection and extraction face material detection purposes to reach the aforementioned objectives. Since these developments are designed to work in underground mining environments within this project, a dedicated thermal imaging demonstrator is designed, built and tested - first extensively in the laboratory, afterwards in relevant environment - for utilization in an underground mine.

In the following use case, thermal imaging is used as a quantitative measuring technology. There is no focus on a back calculation of specific surface temperatures, what is state of the art in many thermal imaging approaches. In addition, thermal imaging is used to visualize material differences by their characteristic thermal radiation and to discover nonuniform material structures through particular heat transfer and distribution effects.

\section{Technological developments}

Within multiple preliminary underground and laboratory measurements, a handheld image capture and processing device as well as appropriate thermal image acquisition and processing techniques were developed. The test mine for evaluating the performance of the roof crack and extraction face material detection system is an active German potash mine operated by $\mathrm{K}+\mathrm{S} A \mathrm{AG}$. The extraction method is drill and blast operation and the material transport is mainly realised by belt conveyors. The potash mine has an ambient temperature of approximately $30^{\circ} \mathrm{C}$, very low humidity and high air 
velocity, which is loaded with salt dust and exhaust fumes. As it is typical for an underground mine, illumination is realised only at strategically important junctions or via mobile light sources. The geology of the potash deposit is rarely regular or flat (see Fig. 1, left) but differs highly due to geological and geomechanical processes since the deposit has formed 250 Mio. years ago. Furthermore, a potash deposit typically consists of multiple layers of different salt rocks with irregular shape and thickness and varying contents of the most valuable component, the Kaliumchloride $\left(\mathrm{K}_{2} \mathrm{O}\right)$ [3]. The mined potassium salt is mainly used for agricultural and food industry, but also for pharmaceutical, metallurgical, construction and several other industries and is therefore tremendously important for our daily life [4].

The purpose for implementing thermal imaging based systems to different underground mining processes is to raise safety and productivity within the mine. Since these goals are hardly measureable directly by comparative values, factors for evaluating success are e.g. the practical usability of a device, the possibility for an integration in the processes value chain and - for sure - it's robustness against the challenging mining conditions.

\subsection{Demonstrator development}

To accomplish the aforementioned tasks applying the above outlined parameters for measuring success, AMT decided to build a battery powered, handheld thermal imaging device. The so-called Demonstrator (see Fig. 1 left.) involves a FLIR Tau 2640 camera core which is connected to an circuit board for image capturing, which was developed in-house, an intel NUC processing computer, a 10" touch display for visualization and operation and an exchangeable battery offering two hours of measuring and processing capacity. Weighing roughly $3 \mathrm{~kg}$, the demonstrator is still portable for a limited amount of time. Equipped with a self-developed housing, a comprehensive sealing for the display, battery pack and germanium window and industrial grade external interfaces, the device is designed to be demonstrated in underground mining environments. The right image in Fig. 1 shows the demonstrator being used for crack detection purposes underground in the Zielitz mine by the person on the right, whilst the person on the left holds a halogen lamp for testing thermal contrast improvement, which will be described later on.
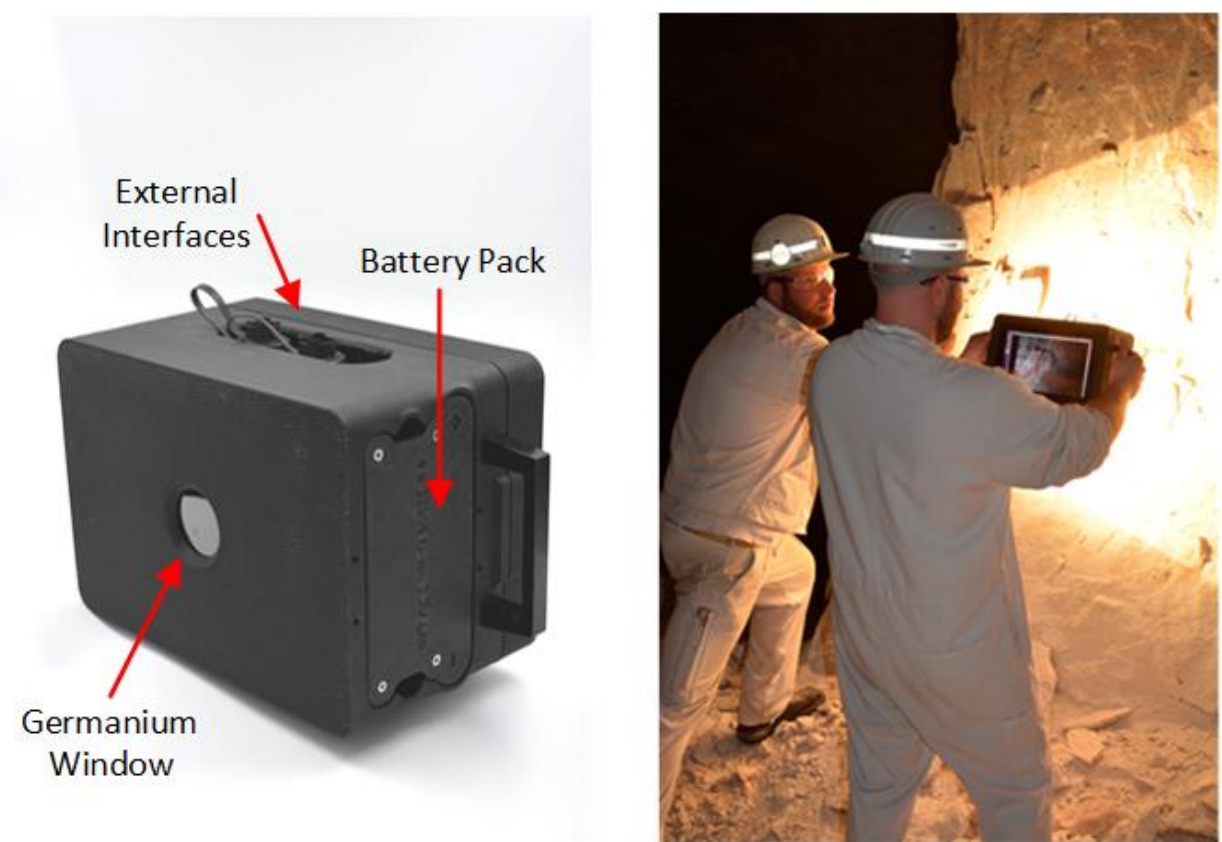

Fig. 1: The Demonstrator with part descriptions (left) and in underground use by an operator (right)

The developed demonstrator is used to demonstrate the functionality of the following two thermal imageprocessing algorithms for extraction face material and roof crack detection in a relevant environment.

\subsection{Extraction face material detection}

One task within the project is the extraction face material detection. Knowing the material composition of a potash mine's extraction face is important for several reasons. On the one hand, a potash mine's success and failure is strongly related to the amount of the $\mathrm{K}_{2} \mathrm{O}$ within the mined ore. If it becomes possible to assess the $\mathrm{K}_{2} \mathrm{O}$ content directly at the mine face, all following processes such as conveying, crushing and processing may become controllable at a very early stage of the value chain. In addition, identifying the direction of the geological boundaries between the salt layers may help to estimate a deposit's main direction and therewith navigate the extraction progress to the location of the valuable material [9]. 
With thermal imaging, it is possible to distinguish different thermal radiation characteristics of salt rocks and thus develop thermal image processing algorithms to perform material detection directly at the mine face. In this case, the challenge is to enable the differentiation of the two salt rock types present in the extraction face. Fig. 2 shows a visual image (left); a thermal image (middle) and processed thermal image (right) of an extraction face in the Zielitz potash mine. The visual image shows that depending on the mineralogical composition of the face material, a distinction between the two different salt rock types can be challenging using only the difference in colour as indicator and main differentiator. The thermal image (middle) is captured with a five metres distance from the extraction face with a FLIR Tau 2640 camera with a focal length of $19 \mathrm{~mm}$; thus the part of the extraction face captured by the image is approx. $2,5 \times 3$ metres [10]. At first, a self-developed contrast adjustment is performed for the entire image, to expand the image's contrast to a full 16-bit spectrum (middle image's stage). Second, a region based thresholding function with size-adjustable window is applied to the image. The processed image shows the extraction face material in a binary format, indicating the differences in characteristic radiation of the two salt rocks. This images information may be used for an approximation of the face's mineralogical composition, as input for geological face mapping or, in combination with the following process steps, as an underlying scheme to design the drill pattern for the upcoming production cycle.
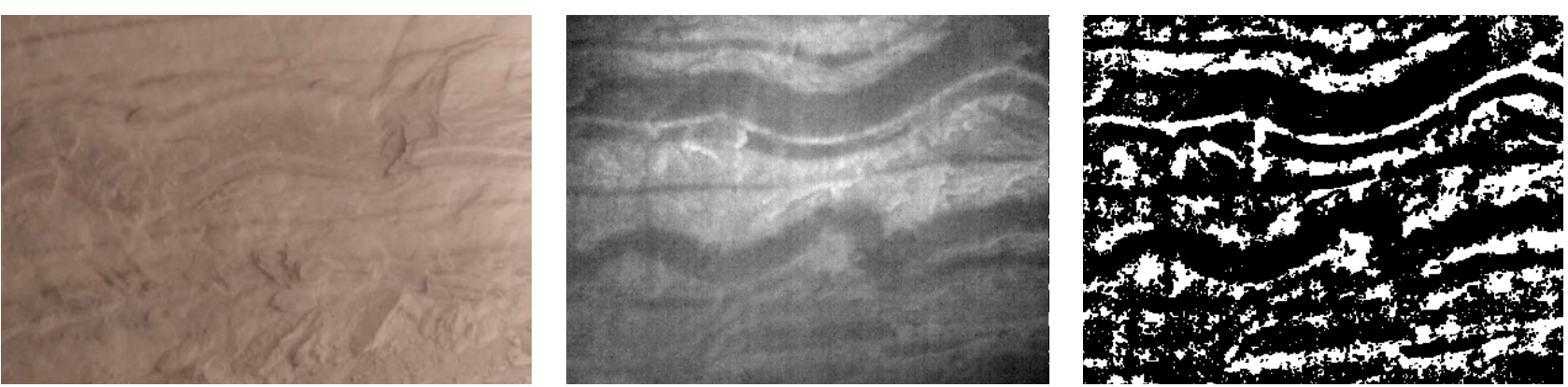

Fig. 2: Visual image (left); thermal image (middle) and processed image (right) of an extraction face

The aim of the extraction face material detection was reached by customizing thermal image processing algorithms to the characteristic thermal radiation of different salt rock materials. Whilst this it became apparent, that some salt rocks e.g. Sylvinite and Carnallite, which are to different salt types that occur layered together, offer better separability than others e.g. Anhydrite and Rocksalt. In all cases, the short-term activation of the mining face by halogen lamps boosted the radiation differences but at the same time amplified disturbing factors as e.g. reflections and by this lowered the comparability between multiple measurements.

\subsection{Roof crack detection for raising safety}

Another task in the SIMS project is the crack detection. After the extraction process, the environment must be scanned and secured. In this case, an infrared camera detects possible cracks caused by the extraction cycle. This is for the safety of the workers. Cracks in the roof can cause parts of the roof to become unstable. These unstable parts can fall down and thus could endanger workers. Crack detection by thermal imaging is supposed to reduce the danger and keep workers away from dangerous and hazardous environments. This challenge is tackled using a multi thresholding algorithm and an additional halogen spotlight for thermal activation to intensify the black body cavity effect.

To ensure workers safety and protect miners as well as the equipment, rock scaling is being conducted in mines as a step of the drill and blast cycle. As part of the mine aftercare, the roofs have to be checked regularly for potential roof falls, due to roof cracks or loosened rocks, as the overburden is settling in older mine parts. Currently, this is done manually by geologists or specially-trained personnel. To speed up this process as well as to ensure workers safety, thermal imaging using long-wavelength infrared can be applied for roof crack and bed separation detection. Due to the diverging angles of emission in the crack zones, roof cracks can be made visible. Because of the different temperatures, due to underground mine ventilation and different emissivity resulting from this, loosened rocks or bed separations become apparent in the thermal images. Using advanced image processing algorithms even small variances in emissivity can be identified and thus used for differentiation purposes. If applied on moving machinery, this process can be sped up significantly. To reach this goal, passive and active scanning methods have to be evaluated to ensure reliable and useful raw images. The cameras themselves have to be ruggedized and housed on the machinery. Lastly, the imaging algorithms need to be developed and adapted to the movement speed of the machine to gather conclusive information.

AMT started the predevelopment of the roof crack detection system by using recorded data from a previous project to assess its usability in the SIMS project. The first step was to conduct preliminary tests in an operating German potash mine. The recorded data served to assess how the results of a previous project can be adapted to the use case in the SIMS project. The hardware (housing, circuit board, mounting, etc.) of the camera already existing at AMT was enhanced and adapted to the challenging conditions in an underground potash mine.

The development started with a systematic measuring campaign at the test mine by applying the improved hardware. In this measurement campaign infrared images of roof face cracks were recorded as a necessary data base for 
further development of existing evaluation algorithms. For conducting the test measurements in the potash mine, several influencing parameters were considered.

The recorded thermal images from the measuring campaign were used for the development of the evaluation algorithms. Requirements for the algorithms are the detection of relevant cracks at roof and face at an early stage, the detection of these cracks from different angles and distances between face/roof and infrared camera as well as its functionality from a moving platform.

After finishing the evaluation algorithm development, a further measuring campaign as part of the demonstration phase, the hardware and software developed during the initial development phase has been validated. Enhancement of algorithms and hardware were conducted before the demonstration actions started. The final test measurement is to test the running system on a driving car in an operating test mine. After the final test the new roof crack detection system is anticipated to be available at a demonstrator level [11].

The developed algorithm was tested on loosened rock and cracks. The following images show the results for the loosened rock and the cracks based on recorded data in Zielitz underground mine.

In order to run the evaluation automatically and in real time, the code developed in Matlab was transferred to the robot operating system (ROS). After the transfer, an evaluation of the cracks and the loosened rock in real time was possible. In addition, the evaluation has also been sent to tablet computers in real time via Wireless LAN connection. The algorithm works so effectively that there was only very little latency in the transfer. The results are displayed in the Fig. 3.

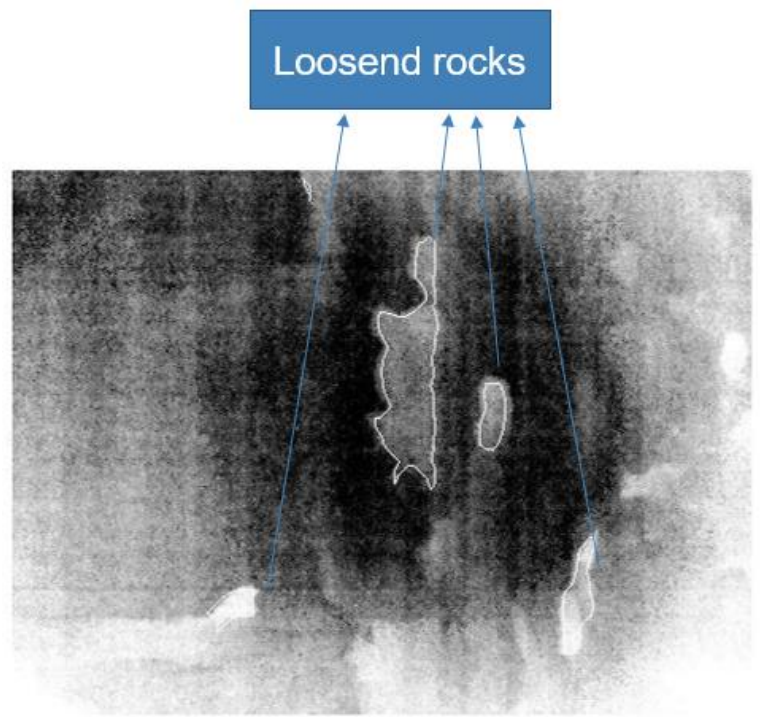

\section{Roof cracks}

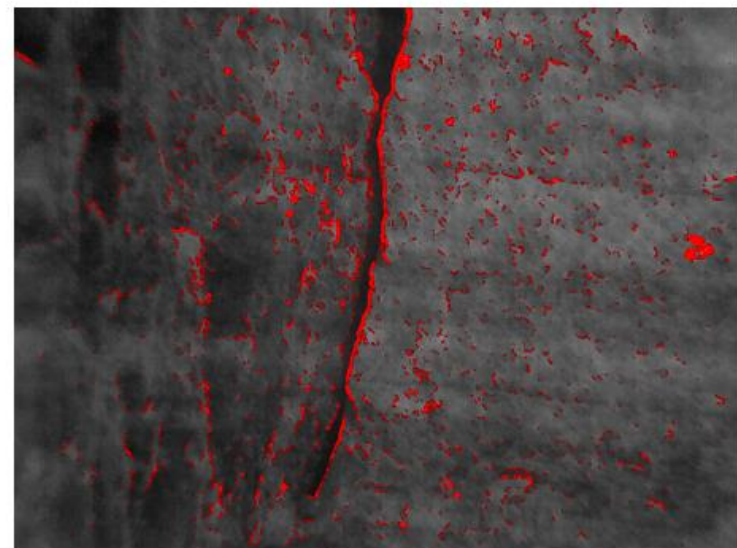

Fig. 3: Processed thermal image of loosened rocks (left); roof cracks (right)

The left image shows a processed thermal image of loosened rocks. The loosened rocks can cause danger and risks for machinery and employees as described above. These should be predictable or not occur by the algorithm.

In the right picture you can see a crack in the face of approx. $2 \mathrm{~cm}$ width, which was detected in a distance of 1 $\mathrm{m}$ with a FLIR Tau 2 WFOV $(\mathrm{f}=19 \mathrm{~mm}$ ) camera. The crack detection algorithm was trained under laboratory conditions, afterwards tested, and further evaluated under mining conditions in a test mine.

\subsection{Material flow characterization}

At AMT, thermal imaging has been successfully used for years in industry-related automation and process control projects. Thus, based on thermal images, various material flows were analyzed by means of image analysis and characteristic analysis. The generated information is used for example, to automatically control the addition of water or to automate the separation of hot material. Other applications allow e.g. the automated loading of mobile conveyor systems in surface mines with the aid of an algorithm-based evaluation of LWIR images of the material transfer point. In the SIMS project, a laboratory study for examining the distinguishability of different salt rocks, conveyed on a belt was conducted using a machine learning approach (see Fig 4). Our circulating test bench allows us to research on belt conveyed volume flows under laboratory conditions. The applied material is circulated on four belts, which are adjustable in conveying speed each. Sensors are mounted at certain points of the test bench, e.g. the thermal imaging camera, which is located above the right band. On the top right of the Figure 4, a raw thermal image of a salt rock volume flow is shown. The thermal image processing procedure for this type of volume flows is used in various former projects at the AMT and thus described at a second example in the following. 


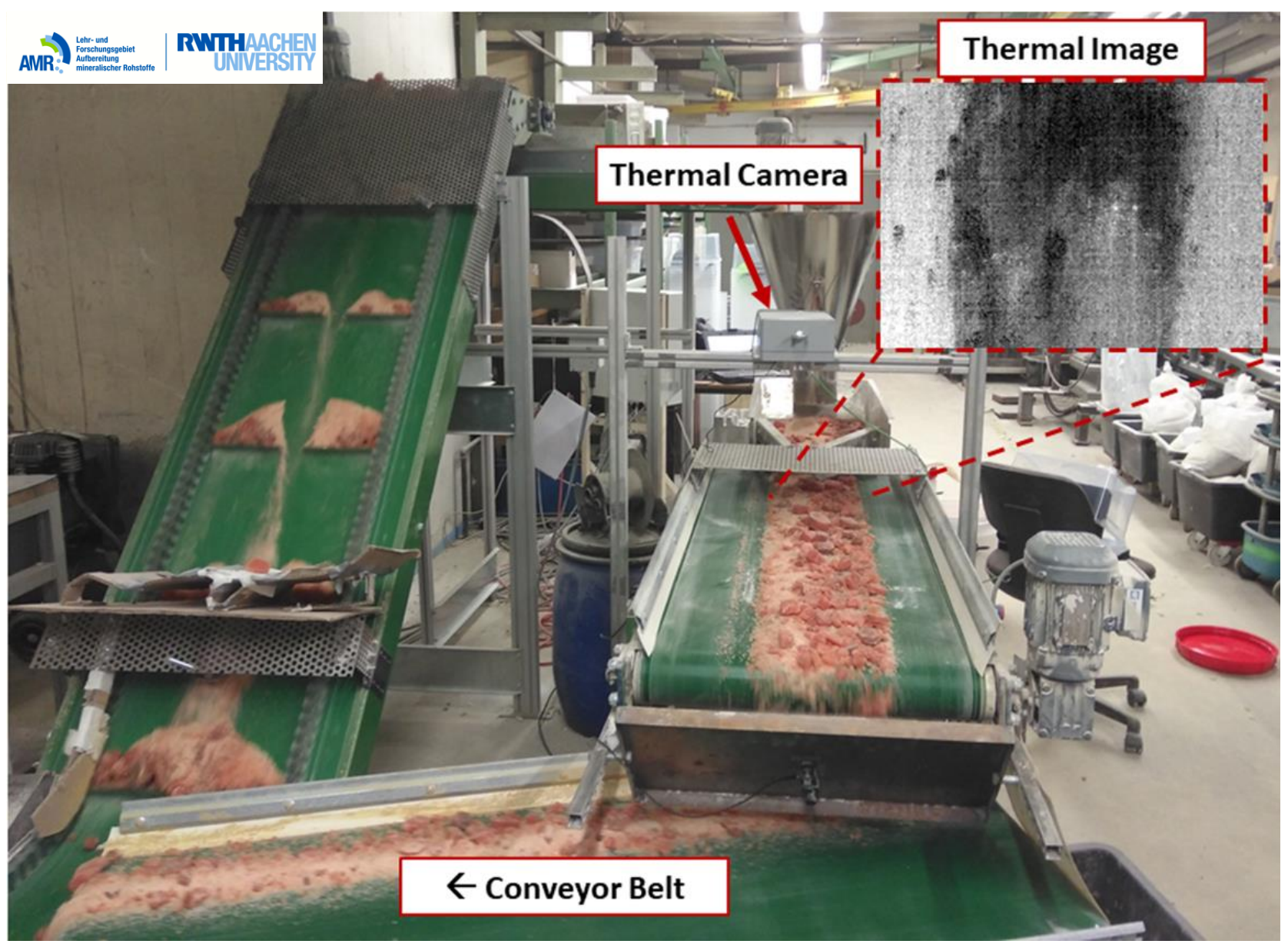

Fig. 4: Circulating test bench of the Mineral Processing Unit at the underground testing lab

An application, which is already in industrial use, is the automated moisture recognition of power plant ash. The conditions in this application are similar to underground mining. It is a very dusty environment. Therefore, the example is listed here as another application. The ash is moved into a bunker in the boiler after the combustion process. From this bunker, the ashes fall onto a conveyor belt, above which the LWIR camera is mounted. The camera continuously records the material flow and uses a specially developed algorithm to determine the moisture content of the ash. This is important because from there the ash reaches a long-distance conveyor belt from which it is returned to the open pit mine. In the open pit mine, the ash is stored. If the moisture content of the ash is too high or too low, it can cause chemical reactions and dangerous situations.

For the development of the automated moisture recognition system an identical test bench was set up in the laboratory of AMT. This consists of a structurally identical control cabinet with all components and associated software. For testing the algorithm, images were recorded by the LWIR camera at the power station [6]. These were played via an application called a camera dummy. Thus, the algorithm could be developed on site in the laboratory and tested sufficiently.

The recorded LWIR images are evaluated in real time using a specially developed algorithm. The algorithm controls a PID controller and the PID controller operates a valve that opens depending on the condition of the ash and adds more water or further closes the valve and thus adds less water to the ash. The algorithm then also controls the evaluation [12].

\section{Conclusion and outlook}

The fourth industrial revolution is ongoing, offering a broad variety of smart sensor technologies, powerful image processing techniques and huge potential for process optimization. It can be stated that underground mining offers a uniquely challenging working environment. On the one hand, it constrains technological improvements due to its harsh environments, but, on the other hand, also offers enormous potential for process optimization due to its broad variety of not even yet digitalized processes.

Through the development of thermal image processing algorithms the detection of structural rock cracks, the delineation of geological boundary layers and a classification of conveyed salt rock material flows was achieved. The automatic detection of roof cracks and rock fall might be used to detect and eliminate dangers that threat the miner's health 
before occurrence. Within a second generation of the demonstrator, the design and algorithms will be adapted to mount the device on a mining vehicles roof and conduct a long-term testing. By this, the needs for a continuous implementation in the process of rock fall and roof crack prevention are to figure out. An implementation of the geological boundary layer and material detection could lower the geological uncertainty and by this allow advanced process planning. The gained information could possibly be used to determine the best possible positions for the production drill holes or even allow an automation of the drill and blast extraction process in the future. In the next steps, an automated interpretation of the processed images information is to implement.

This may allow implementing smart services for material characterisation as well as rock fall prevention and the geological surveying for autonomous mine path planning or similar actions.

Subsequently, the material flow characterization of conveyed salt rocks was successfully demonstrated in the laboratory and now needs to be tested within the underground mine. If the tests in the underground mine show comparable results, an implementation of a material characterization for conveyed salt rocks could allow control over the extensive underground conveying processes. By this, valuable and non-valuable material could be separated directly after extraction and thus, before transporting non-valuable material to the surface.

All the aforementioned examples show, that there is high potential for improving safety and productivity in underground mining by the use of thermal imaging. Finally, it may also be stated that extensive testing and a closed loop process thinking are necessary for the successful implementation of technological developments in mining.

\section{Acknowledgements}

We would like to thank our project task partner $\mathrm{K}+\mathrm{S}$ AG for their support at the mining face and in all project management and geological expertise. This project has received funding from the European Union's Horizon 2020 Research and Innovation Programme under the Grant Agreement No.730302.

\section{REFERENCES}

[1] M. Vollmer and K.-P. Möllmann, Infrared Thermal Imaging. Weinheim, Germany: Wiley-VCH Verlag $\mathrm{GmbH} \& \mathrm{Co} . \mathrm{KGaA}, 2010$.

[2] K. Nienhaus, Ed., Sensor technologies: Impulses for the raw materials industry. Aachen: Shaker, 2014.

[3] F. Bernhard, Handbuch der Technischen Temperaturmessung, 2nd ed. Berlin: Springer Vieweg, 2014.

[4] P. Darling, SME Mining Engineering Handbook, 3rd ed. Littleton: SME, 2011.

[5] F. Mavroudis, Infrarotsensorik zur Grenzschichterkennung: Entwicklung und Einsatz eines

bildgebenden Infrarotsensorsystems bei der Automatisierung von Walzenladern im Untertagebergbau. Zugl.:

Aachen, Techn. Hochsch., Diss., 2011, 1st ed. Stolberg: Zillekens, 2011.

[6] J. Berg, "Entwicklung und prototypischer Einsatz eines Infrarotkamerasystems für

Automatisierungslösungen im Rohstoffsektor," Dissertation, RWTH Aachen, 2016.

[7] T. Vreatz, Entwicklung und Anwendung eines innovativen Konzepts zur Inline-Charakterisierung von

Stoffgemischen in kontinuierlichen Massenströmen mittels der Acoustic Emission Technologie, 2018.

[8] SIMS, SIMS Mining Project. [Online] Available: https://www.simsmining.eu/. Accessed on: Feb. 23

2019.

[9] S. Zeibig and J. Feldberg, Die Kalilagerstätte des Werkes Zielitz und die Steinsalzlagerstätte des Werkes Bernburg der Kali und Salz GmbH, 2018.

[10] FLIR, Tau 2: Longwave Infrared Thermal Imaging Cameras. Santa Barbara, 2013.

[11] B. Eichentopf, T. Wendel, R. Baltes, and K. Nienhaus, "Use cases of thermal imaging in the mining industry," in Nowoczesne technologie i bezpieczeństwo w górnictwie: [monografia], Kraków: Department of Mining, Dressing and Transporting Machines. Faculty of Mechanical Engineering and Robotics, University of Science and Technology, op. 2017, pp. 51-56.

[12] T. Wendel, T. Vraetz, R. Baltes, K. Nienhaus, and E. Clausen, "Inline Analyses of Material Flows by Means of Machine Learning in the Raw Materials Industry," GeoResources Journal, vol. 2019, no. 1, pp. 57-62, https://www.georesources.net/download/GeoResources-Journal-1-2019.pdf. 